\title{
Students' attitudes towards performance heterogeneity and their relation to contextual factors
}

\author{
Stefanie Dotzel ${ }^{1}$ (D) $\cdot$ Meike Bonefeld $^{2} \cdot$ Karina Karst $^{2}$ \\ Received: 7 April 2020 /Revised: 3 February 2021 / Accepted: 2 March 2021 / \\ Published online: 16 April 2021 \\ (C) The Author(s) 2021
}

\begin{abstract}
Previous studies examining attitudes towards performance heterogeneity have focused on attitudes among teachers. However, positive attitudes towards the school environment are also assumed to be conducive for students. The aim of this paper is to examine students' attitudes towards performance heterogeneity with a sample of $7845^{\text {th }}$-grade students. Based on the three-component theory of attitudes (Eagly \& Chaiken, 1993), we investigated whether students' attitudes towards performance heterogeneity are positive or negative. Furthermore, we analyzed contextual relations, focusing on whether students' attitudes are linked to performance heterogeneity in the classroom and to a teachers' behavior to manage performance heterogeneity. Descriptive statistics show that students' attitudes towards performance heterogeneity are rather positive. Multi-level structural equation models reveal that contextual rather than individual characteristics relate to students' attitudes towards performance heterogeneity. Accordingly, students in heterogeneous classes show a more positive attitude towards performance heterogeneity than students in less heterogeneous classes. In addition, a teachers' capability of professionally managing heterogeneity is positively associated with students' attitudes towards performance heterogeneity. Accordingly, students' show more positive attitudes if teachers implement rules, effectively manage disruptions, orient themselves towards temporal reference norms, cultivate a positive error culture, and differentiate instruction in the classroom. We will discuss our results and consider implications for psychological aspects of education and learning.
\end{abstract}

Stefanie Dotzel

stefanie.dotzel@uni-bamberg.de

Meike Bonefeld

bonefeld@uni-mannheim.de

Karina Karst

karst@uni-mannheim.de

1 Department of Psychology, University of Bamberg, Markusplatz 3, 96047 Bamberg, Germany

2 Department of Psychology, University of Mannheim, A5, 6, 68159 Mannheim, Germany 
Keywords Performance heterogeneity - Attitudes towards performance heterogeneity .

Secondary school students $\cdot$ Contextual relationships

\section{Introduction}

The question of how to deal with performance heterogeneity is not a new topic. In recent years, schools have had to deal with a growing proportion of students with a migration background and, in turn, with greater differences in language skills within classrooms (Jensen \& Rasmussen, 2011; Maehler \& Brinkman, 2016). Furthermore, students with special educational needs are more often included in general education, increasing the heterogeneity of learning prerequisites (Markic \& Abels, 2014; Powell, 2006).

Teachers' attitudes play a major role in how this growing heterogeneity is dealt with in the classroom and have been the focus of the prevailing literature (e.g., Dar, 1985; Hartinger et al., 2010; Kumar \& Hamer, 2012; Linchevski \& Kutscher, 1998; Youngs \& Youngs, 2001). However, the class composition (e.g., performance heterogeneity, mean class performance level) does not only affect teachers but also affect students. Regarding students' school-related attitudes, studies show that positive attitudes increase learning motivation, joy, and performance (e.g., Else-Quest et al., 2013; Gaith \& Bouzeineddine, 2011; Papanastasiou \& Zembylas, 2002). Accordingly, students perform especially well if they have a positive attitude towards school, a particular subject, or teacher.

Therefore, attitudes of students play an important role in educational practice and policy. The aim of this study was to analyze the attitudes towards performance heterogeneity (APH) among students. Based on a sample of $7845^{\text {th }}$-grade students, we examined how students' APH can be described and how students' APH relate to individual and contextual factors.

\section{Attitudes as psychological constructs}

Attitudes can conceptually be defined as a psychological tendency that is expressed by evaluating a particular entity with some degree of favor or disfavor (Eagly \& Chaiken, 1993; Krosnick \& Petty, 1995). According to the multi-dimensional theory, attitudes can be distinguished into three classes: cognition, affect, and behavior (Katz \& Stotland, 1959; Rosenberg \& Hovland, 1960). Combined, these three components represent the attitude construct. The cognitive category contains beliefs people have about the attitude object. The affective component consists of emotions people have related to the attitude object. The behavioral category encompasses people's intentions or actions with respect to the attitude object.

\section{Attitude towards performance heterogeneity}

It is already known that teachers perceive increasing performance heterogeneity as a professional difficulty (e.g., Baumert et al., 1997; Cho \& DeCastro-Ambrosetti, 2005; Dooly, 2005; Kumar \& Hamer, 2012). Among students themselves, this question is still unanswered. An investigation of students' attitudes is of high relevance, because it is assumed that $25 \%$ of the variance of students' performance can be explained by attitudes towards the subject, towards self-belief, and towards the school environment (Bloom, 1976). While the influence of 
students' attitudes towards the subject (e.g., Martinez et al., 2008; Papanastasiou \& Zembylas, 2002, 2004) and towards self-belief (e.g., Else-Quest et al., 2013; Gaith and Bouzeineddine 2011) has already been proven to positively influence students' performance, students' attitudes towards the school environment, such as performance heterogeneity, have played a minor role in previous research.

\section{Attitude object: performance heterogeneity}

In attitude theory, anything that can be discriminated can be evaluated and used as an attitude object (Bem, 1972), whereby attitude objects can be either concrete or abstract (Eagly \& Chaiken, 1993). The attitude object performance heterogeneity can be defined as the distribution of population elements along a continuum of homogeneity to heterogeneity with respect to an ability or performance-related variable (cf. Lieberson, 1969; Teachman, 1980). Accordingly, students in rather homogeneous classes have rather similar cognitive abilities or performance levels, and students in rather heterogeneous classes have divergent cognitive abilities or performance levels.

\section{The impact of performance heterogeneity on students' APH}

Performance heterogeneity plays an important role in educational research and practice, because teachers face the challenge of dealing with performance heterogeneity professionally. However, performance heterogeneity affects both teachers and students. Performance heterogeneity is a contextual circumstance in which students learn and interact with each other. Students in classes with different compositions have different experiences with performance heterogeneity; these experiences are expected to influence students' APH. Even if previous research has not focused on students' APH, the literature reports findings regarding teachers' APH and students' attitudes towards inclusion, which can be used as a theoretical foundation.

Studies investigating teachers' APH reveal that teachers show a more positive APH if they have already had contact with heterogeneity. Accordingly, a study by Linchevski and Kutscher (1998) showed that teacher participation in a project regarding mixed-ability grouping had a positive influence on their attitude towards teaching mixed-ability classes. Their analyses also show that teachers' attitudes became more positive the longer they participated in the project. Additionally, a study by Hartinger et al. (2010) compared the APH of teachers in mixed-age (heterogeneous) and same-age (homogeneous) classes in primary school. Their results revealed that teachers from mixed-age classes were significantly less likely to pursue a homogenization goal and more likely to view heterogeneity as an enrichment. Another study showed that teaching in heterogeneous classes led teachers to have a more positive APH (measured by a teachers' preference to teach a heterogeneous class in future) (Dar, 1985). Furthermore, Byrnes and Kiger (1997) found similar results for attitudes towards language diversity, proving that such attitudes can be predicted by a teacher's previous experience. If teachers had already been in contact with linguistic-minority students, they had a more positive attitude towards language diversity.

Studies investigating students' attitudes towards inclusion of children with disability follow a similar pattern. Hence, a meta-analysis by Nowicki and Sandieson (2002) showed that, in general, students preferred their classmates to be children without disabilities $(\mathrm{ES}=0.71)$, but students from integrative classes had more positive attitudes towards children with disabilities compared to their classmates in regular classes $(\mathrm{ES}=0.32$ ). Another meta-analysis, which was recently conducted by Armstrong et al. (2016), found that direct and extended contact with students with disabilities 
(physical disability, learning disability, specific diagnoses) led to more positive attitudes towards students with disabilities among students $\left(\mathrm{ES}_{\text {direct contact }}=0.55 ; \mathrm{ES}_{\text {extended contact }}=0.61\right)$.

Some of these studies claim that their results can be explained by the contact hypothesis according to Allport (1954) (e.g., Armstrong et al., 2016; Byrnes \& Kiger, 1997). The contact hypothesis states that frequent contact with groups or individuals towards which or whom prejudices have been formed reduces these prejudices and helps individuals develop a positive attitude. Contact is assumed to be particularly effective if people in the contact situation pursue cooperative goals, are of the same status, and interact with each other, and if contact is supported by the authorities. As already stated, performance heterogeneity is a contextual circumstance that students are confronted with. According to the contact hypothesis, this could mean that students have a more positive APH if they are part of a heterogeneous class. Because students in a class pursue common goals (e.g., passing the class, acceptance for colleges), interact with each other (e.g., discussions, group work, joint assignments), and are supported by their teacher, performance heterogeneity is assumed to positively influence students' APH.

\section{The impact of teacher behavior on students' APH}

In addition to performance heterogeneity, a teacher's behavior of how to establish the learning environment might be significant for developing a positive APH in students. If a teacher cannot ensure that the disadvantages of heterogeneous classes (e.g., disturbances, understraining and overstraining students) are limited and that the advantages (e.g., students of different cognitive abilities working together) are used for social and cognitive learning (Slavin, 1990), students have no opportunity to gain positive experiences with performance heterogeneity and therefore cannot develop a positive APH.

Professionally dealing with performance heterogeneity is quite complex and difficult to implement. Teachers encounter several challenges with performance heterogeneity and must implement strategies in order to professionally manage it (Pietsch, 2010). The state of research and the existing literature provide teachers with the following strategies: Firstly, teachers must establish a simple, well-structured learning environment through efficient classroom management (e.g., Emmer et al., 2006). Secondly, teachers must cultivate a learner-centered teacherstudent relationship (e.g., Cornelius-White, 2007). And, thirdly, teachers need to differentiate instruction in order to assure adequate learning support for students of different ability groups (e.g., Hattie, 2009).

\section{Classroom management}

In order to positively change students' APH, stable classroom management by teachers is vital. Classroom management is relevant for effective teaching and can be defined as "the ability to establish, maintain and (when necessary) restore the classroom as an effective environment for teaching and learning (Brophy, 1986)." Literature suggests two strategies for effective classroom management: First, it is important to instruct students in rules (e.g., Emmer et al., 2006; McGinnis et al., 1995; Van de Grift, 2007), and second, teachers need to monitor student compliance with the rules by effectively managing disruptions (e.g., Anderson et al., 1979; Brophy \& Evertson, 1976; Evertson et al., 2006; Pedota, 2007).

Clarification of rules with detailed instructions and modeling prevents a high amount of disturbance and gives students clear guidance (Evertson \& Emmer, 1982). This is essential for professionally managing heterogeneity and is assumed to positively influence students' APH. 
In addition, rapid intervention when students behave inappropriately is assumed to promote students' APH. Especially in heterogeneous classes, the way students understand compliance and working behavior might highly vary, and it is important that teachers remind students about rules and provide extra instruction until students follow rules automatically (Brophy, 1986). If teachers succeed in implementing both strategies - preventing and effectively managing disturbances - they create a fruitful basis for successful learning, which enables students to develop a positive APH.

\section{Learner-centered approach}

Furthermore, students' APH might be positively affected by teachers using a learner-centered teaching approach. The learner-centered approach connects a focus on individual learners with a focus on learning (McCombs \& Whisler, 1997). It involves teacher and students interacting successfully - interaction that is characterized by sensitivity, respect, and quality of relationship (e.g., Cornelius-White, 2007; Kunter \& Voss, 2011; Pianta \& Hamre, 2009). To ensure a learner-centered environment, two strategies are particularly appropriate: First, teachers orient themselves towards temporal reference norms (e.g., Dickhäuser et al., 2017; Rheinberg, 1980), and second, teachers foster a positive error culture in the classroom (e.g., Keith \& Frese, 2008; Nordstrom et al., 1998; Rach et al., 2013).

A reference norm orientation (RNO) applies to the assessment of students' performance and distinguishes between three approaches: criterion-based RNO (comparing individual performance with an absolute standard), social RNO (comparing individual performance with the performance of other students), and temporal RNO (comparing individual performance with past results) (Rheinberg, 1980). In order to positively influence students' APH, teachers should apply temporal RNO. In heterogeneous classes, differences in performance are highly pronounced and, therefore, more easily noticed by students. This can lead to a larger gap between students and tensions in the class, negatively influencing students' APH. However, if teachers highlight individual learning development, they blur differences in ability, shifting students' focus from social comparison to their own learning growth, and thus, students are more likely to develop a positive APH. Another learner-centered approach which supports a positive APH among students is an error-friendly feedback culture. Because in heterogeneous classes students' cognitive abilities vary substantially, comprehension problems, misconceptions, and wrong answers may occur more frequently. Especially, the latter trigger a feeling of unpleasantness in students and increases emotional discomfort (Kunter \& Trautwein, 2013). To promote students' APH, it might be crucial that teachers integrate these errors in order to explain thought processes and stimulate discussions (Tulis, 2013). In doing so, teachers derive a benefit from class heterogeneity and provide students with the opportunity to develop a positive APH.

\section{Differentiated instruction}

A final aspect for fostering a positive APH among students is differentiated instruction. Differentiated instruction adapts to the individual ability level of each student, with teaching materials designed in a differentiated and stimulating way (e.g., Hattie, 2009; King-Sears, 2008; Vaughn et al., 2001).

Students are frequently understrained and overstrained in everyday school life, leading to boredom and monotony, which are perceived as the strongest school-related problems for 
students (e.g., Larson \& Richards, 1991; Perkins \& Hill, 1985). These factors play a role especially in heterogeneous classes, where students are more often understrained and overstrained. By didactically focusing on the individual learner (e.g., enabling discussions and groupwork between students of different ability levels, differentiating individual work in difficulty levels), teachers deal professionally with heterogeneity and cognitively activate each individual student. In this way, each student benefits from the heterogeneity of the class, which is assumed to positively influence APH.

\section{Hypotheses}

To date, there has been no literature regarding students' APH. However, in Bloom (1976)'s theory of school learning, it is assumed that students' attitudes towards the school environment influence their learning and performance. Therefore, the aim of our study was to examine students' APH and its relationship with contextual factors.

In the following, we present our hypothesis concerning performance heterogeneity:

1. Performance heterogeneity in the classroom positively relates to students' APH.

Based on the contact hypothesis according to Allport (1954), we assumed that contact with an attitude object would be positively linked to the attitude itself. Studies on attitudes towards APH among teachers (e.g., Byrnes \& Kiger, 1997; Dar, 1985) as well as studies on attitudes towards inclusion among students (e.g., Armstrong et al., 2016; Avramidis \& Norwich, 2002) suggest this pattern, and we therefore expected the same pattern for APH among students. We assumed that students from classes with higher heterogeneity would show a more positive $\mathrm{APH}$.

In the following, the hypotheses regarding classroom management are presented:

2a. Implementing rules positively relates to students' APH.

2b. Effectively managing disturbances positively relates to students' APH.

Both strategies contribute to effective classroom management, which is an important foundation for students to develop a positive APH. If teachers prevent disturbances using rules (Hypothesis 2a) and respond to disturbances effectively (Hypothesis 2b), students should have a more positive APH.

In the following, the hypotheses related to the learner-centered approach are presented:

3a. A temporal RNO positively relates to students' APH.

3b. A positive error culture positively relates to students' APH.

Both strategies contribute to a learner-centered environment. Teachers applying a temporal RNO (Hypothesis 3a) level out differences in performance between students and focus on individual learning development. Teachers fostering a positive error culture (Hypothesis $3 b$ ) integrate errors into their instruction. Both strategies are expected to positively relate to APH among students.

In the following, we present our hypothesis regarding differentiated instruction: 
4. Differentiated instruction positively relates to students' APH.

Differentiated instruction reduces monotonous teaching phases. Furthermore, orientation towards individual performance levels increases the cognitive activity of students. We thus assumed that professionally managing performance heterogeneity by differentiating instruction is positively associated with students' APH.

\section{Method}

\section{Sample and design}

At the beginning of the school year 2018/2019, a survey of students and their teachers was conducted. Each student took part in a language proficiency test and subsequently completed a questionnaire. In the student questionnaire, data on individual demographics, students' APH, and contextual teaching variables (i.e., implementation of rules, disturbance management, temporal RNO, positive error culture) were collected. The sample consisted of $N=7845^{\text {th }}$ grade students $\left(50 \%\right.$ female; $M_{\text {age }}=10.20$; standard deviation $\left.(S D)=0.51\right)$ from 33 classes. Their teachers (65\% female; on average between 35 and 45 years old) were interviewed on their individual demographics and the extent to which they differentiate their instruction $(N=$ 21 because of low response rate) ${ }^{1}$. The data were collected in 12 secondary schools (eight Gymnasien, two Realschulen, two Gemeinschaftsschulen). The average class consisted of 25 students; $65 \%$ of the students had a migration background, which means that at least one parent was born abroad (Statistisches Bundesamt, 2018).

\section{Instruments}

\section{Attitude towards performance heterogeneity}

APH was measured multi-dimensionally using three separate scales for the cognitive, affective, and behavioral components. To measure the attitude components, an agreement-rejection dimension was used with respect to the attitude object performance heterogeneity. The items are based on a six-level Likert scale and have a bipolar structure. The two respective poles are provided with response categories and differ in their valence. The higher the agreement, the more positive the attitude of students towards performance heterogeneity. Students' APH was measured based on their attitude in the subject German. The cognitive attitude dimension was measured with a total of 13 items reflecting students' thoughts about performance heterogeneity (e.g., I think a class in which the students' performance in German differs is... [bad]-[good]). The affective component was measured using 15 items reflecting students' emotions towards performance heterogeneity (e.g., In a class in which students' performance in German differed, I would be... [stressed]-[relaxed]). The behavioral component was measured using five items to capture the intentional behavior of students (e.g., If I had the

\footnotetext{
${ }^{1}$ Results of a $t$ test revealed that there were no significant differences in performance heterogeneity $(p=.23)$ between the classes for which the teachers responded $(M=9.88)$ and those for which the teachers did not respond $(M=10.89)$.
} 
choice, I would prefer to be in a class in which students perform... [similarly to me]-[differently to me]).

\section{Performance}

An adapted version of the Duisburg language proficiency test was used to collect performance data (Karst et al., 2021; Theunissen et al., 2005). This adapted version comprises four subscales: listening comprehension, grammar, sentence structure, and vocabulary. Listening comprehension $(\alpha=.73)$ was assessed using an audio recording which the students listened to once. Afterwards, students were allowed to read and answer ten single-choice questions (each with four possible answers) within $8 \mathrm{~min}$. The students' grammar performance $(\alpha=.82)$ was measured by combining two different tests. In test A, students had to complete a sentence with the grammatically correct form using one or several given words. Test B consisted of ten single-choice questions (each with four possible answers) which required students to complete a sentence using the grammatically correct form. The sentence construction test $(\alpha=.75)$ consisted of 40 items in a binary $0-1$ format. Students had to decide whether the sentence structure was correct or incorrect. In the vocabulary test $(\alpha=.86)$, the students had to find a synonym for a given word. It was based on a single-choice format with four possible answers for a total of 20 items.

The four subtests were weighted to allow a maximum of 20 points each. Together, they represented students' final language proficiency score. Thus, the maximum test score was 80 points. Raw data (dichotomously coded) formed the basis for scaling according to the 2-PL IRT model. Scaling was performed with R (R Core Team, 2019). No items had to be excluded due to poor item fits (WMNSQ $>1.2$ or $<0.8$ ).

\section{Performance heterogeneity}

Performance heterogeneity was calculated with the intra-class SD based on the final score of the Duisburg language proficiency test.

\section{Teacher behavior}

Students assessed the extent that rules apply in class $\left(n_{\text {items }}=4 ; \alpha=.80 ;\right.$ ICC $1=5.99 \%$;CC2 $=.61$; e.g., With my teacher, everyone knows the rules that must be followed. $1=$ not true at all, $4=$ absolutely true) and the teacher's effective management of disturbances $\left(n_{\text {items }}=4 ; \alpha=\right.$ $.71 ;$ ICC $1=13.15 \%$; ICC2 $=.79$; e.g., My teacher ends disturbances by students quickly and without discussion. $1=$ not true at all, $4=$ absolutely true) (Piwowar, 2013). Students also assessed teachers' use of temporal RNO $\left(n_{\text {items }}=4 ; \alpha=.76\right.$; ICC $1=0.94 \%$; ICC $2=.20$; e.g., If I make a special effort, my teacher usually praises me, even if other students are better than me. 1 = not true at all, $4=$ absolutely true) (Jerusalem et al., 2009) and fostering of a positive error culture by the teacher $\left(n_{\text {items }}=4 ; \alpha=.78\right.$; ICC $1=3.61 \%$; ICC2 $=.48$; e.g., If I make mistakes in class, my teacher discusses them with me in such a way that it really helps me. $1=$ not true at all, 4 = absolutely true) (Piwowar, 2013). Differentiated instruction was assessed by the teachers themselves. Teachers were asked to assess the extent to which they differentiate instruction in class $\left(n_{\text {items }}=11 ; \alpha=.91\right.$; e.g., When students work individually, I vary the task to meet the needs of students with varying abilities. $1=$ do not agree at all, $4=$ agree absolutely) (based on Baumert et al., 2008; Rheinberg, 1980). 


\section{Data analysis}

First of all, a confirmatory factor analysis (CFA) was performed to uncover basic relationships between the attitude items and to analyze the structure of students' APH. In this process, we controlled for class affiliation. The respective items model the three components: cognitive, affective, and behavioral attitudes. Together, the three subcomponents represent the latent construct APH among students (Dotzel \& Karst, 2021). Secondly, descriptive analyses were conducted to identify the value of students' APH and to analyze the relationship between the three attitude components. Finally, to uncover the relationships between students' APH and contextual factors (Hypotheses 1-4), we calculated seven multi-level structural equation models. The loadings of the attitude variables and attitude components were fixed at level 1 and level 2.

Model 0, the baseline model, examined the relationship between individual demographics, which we defined as control variables - gender ( $0=$ male; $1=$ female), migration background ( $0=$ both parents born in Germany; $1=$ at least one parent born abroad), and cultural capital (how many books do you have at home? 1 = None or only very few; $5=$ Over 200 books)and students' APH. Model 1 addressed Hypothesis 1: the assumption that performance heterogeneity in the classroom would positively correlate with student' APH. Here, individual performance and average class performance were used as additional control variables. Furthermore, we controlled for school type by including binary school-type variables as predictors for performance heterogeneity and average class performance (see Fig. 1). Models 2-6 examined the link between teachers' professional management of performance heterogeneity and students' APH. Models 2-6 extended model 1, adding one predictor each. Models 2-5 included the respective predictors on student level 1 and class level 2, and model 6 on class level 2 only.

Individual test performance was centered at the group mean because it depended on the respective class (Enders \& Tofighi, 2007). All other independent continuous variables were $z$ standardized. We used the R package lavaan to run our models (Rosseel, 2012). In all models, we imputed for missing data using fiml.

\section{Results}

Based on the CFA, we excluded one item (c_10) because of its poor fit $(\lambda=.19)^{2}$. The CFA showed an acceptable model fit with a comparative fit index $(\mathrm{CFI})=.928$, Tucker-Lewis index $(\mathrm{TLI})=.922$, root mean square error of approximation $($ RMSEA $)=.047$ (Browne \& Cudeck, 1993; Byrne, 1994), and a relative chi-square index with $\chi^{2} / d f=2.593$ (Kline, 1998; Ullman, 2001). The calculation of the attitude components showed very good reliabilities with $\alpha_{\operatorname{cog}}=$ $.91, \alpha_{\text {aff }}=.95$, and $\alpha_{\text {beh }}=.90($ see Table 1$)$.

\section{Descriptive analyses}

The descriptive statistics revealed a positive value for students' attitudes towards performance heterogeneity (Table 1$)$. With a theoretical mean of 3.5 ( 1 = negative attitude;

\footnotetext{
${ }^{2}$ We provide a table with the factor loadings of the confirmatory factor analysis in the supplementary material online. Please see SM01_Standardized Factor Loadings.
} 


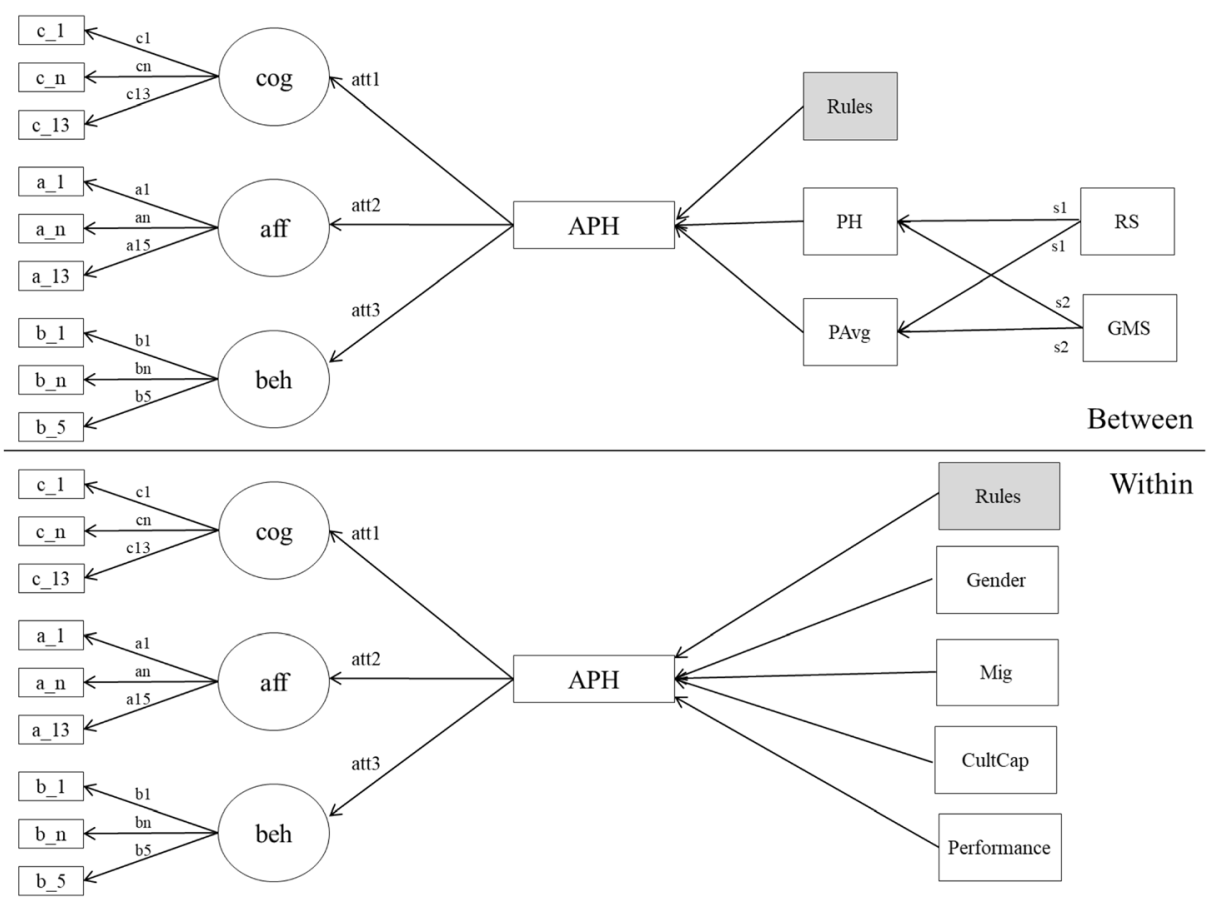

Fig. 1 Multi-level structural equation model using Hypothesis $2 \mathrm{a}$ as an example. cog, cognitive component; aff, affective component; beh, behavioral component; APH, students' attitudes towards performance heterogeneity; Mig, students' migration background ( $0=$ both parents born in Germany; $1=$ at least one parent born abroad); Gender ( 0 = male; 1 = female); CultCap, cultural capital; PH, performance heterogeneity; PAvg, average performance; RS, Realschule; GMS, Gemeinschaftsschule

$6=$ positive attitude), the cognitive $(M=4.1)$ and affective $(M=4.3)$ components were in the positive area of the scale. Hence, students showed rather positive beliefs and emotions towards performance heterogeneity. The behavioral component had a mean value of $M=3.5$, the exact mean of the scale. Furthermore, Fig. 2 shows the distribution function of the respective attitude component and reveals differences between the cognitive $(S D=1.1)$ and affective $(S D=1.1)$ components and the behavioral $(S D=$ 1.6) component. We found positive correlations between the attitude components (see Table 1). Students who have positive beliefs about performance heterogeneity are more likely to show positive emotions about performance heterogeneity $\left(r_{\text {cog aff }}=.64 ; p<\right.$ $.001)$ and are more likely to choose a heterogeneous class $\left(r_{\text {cog_beh }}=.22 ; p<.001 ; r_{\text {aff_beh }}\right.$ $=.27 ; p<.001)$.

Table 1 Psychometric properties and correlations for the cognitive, affective, and behavioral attitude components

\begin{tabular}{|c|c|c|c|c|c|c|c|c|c|c|c|}
\hline & $n$ & Min & Max & Mean & SD & Skew & Kurtosis & $\alpha$ & $\operatorname{cog}$ & aff & beh \\
\hline $\operatorname{cog}$ & 720 & 1 & 6 & 4.11 & 1.06 & -.14 & -.24 & .91 & - & & \\
\hline aff & 724 & 1 & 6 & 4.30 & 1.12 & -.50 & -.34 & .95 & $.64 *$ & - & \\
\hline beh & 719 & 1 & 6 & 3.52 & 1.58 & -.01 & -1.06 & .90 & $.22 *$ & $.27^{*}$ & - \\
\hline
\end{tabular}

$\operatorname{cog}$ cognitive component, aff affective component, beh behavioral component

$* p<.001$ 


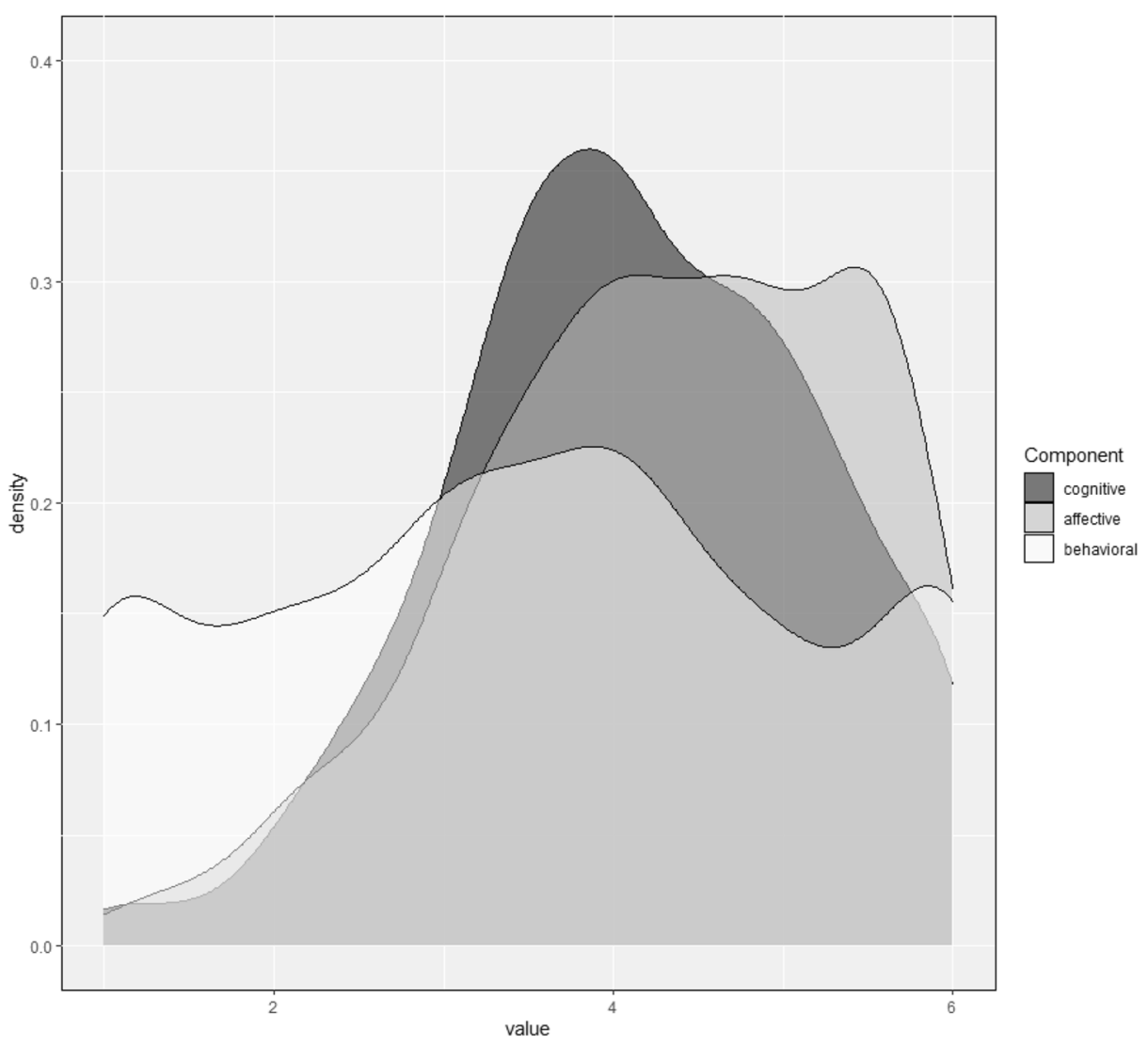

Fig. 2 Density plot for the attitude components

\section{Relationship between contextual factors and students' APH}

Table 2 shows the relationships between contextual factors and students' APH. Model 0 , the baseline model, determined the link between the control variables (i.e., students' individual demographics) and APH. Models 0-6 revealed that none of the students' individual background characteristics relates to APH (except students' migration background in model $0(\beta=.11 ; p<.05)$ and model $6(\beta=.22 ; p<.05))$.

\section{Performance heterogeneity}

Hypothesis 1 examined whether a classes' performance heterogeneity is linked to students' APH (see model 1, Table 2). The results revealed that performance heterogeneity in a class positively correlates with students' APH $(\beta=.09 ; p<.05)$. This correlation remains stable when controlling for individual performance $(\beta=-.00 ; p=$ $.607)$ and average class performance $(\beta=.01 ; p=.877)$, both of which do not significantly relate to $\mathrm{APH}$. 
Table 2 Multi-level structural equation models predicting students' attitudes towards performance heterogeneity

\begin{tabular}{|c|c|c|c|c|c|c|c|}
\hline Path & $\begin{array}{l}\text { Model } 0, \beta \\
(\mathrm{SE})\end{array}$ & $\begin{array}{l}\text { Model 1, } \beta \\
(\mathrm{SE})\end{array}$ & $\begin{array}{l}\text { Model 2, } \beta \\
(\mathrm{SE})\end{array}$ & $\begin{array}{l}\text { Model 3, } \beta \\
(\mathrm{SE})\end{array}$ & $\begin{array}{l}\text { Model 4, } \beta \\
(\mathrm{SE})\end{array}$ & $\begin{array}{l}\text { Model 5, } \beta \\
(\mathrm{SE})\end{array}$ & $\begin{array}{l}\text { Model } 6, \beta \\
(\mathrm{SE})\end{array}$ \\
\hline \multicolumn{8}{|l|}{ Within class level } \\
\hline $\mathrm{APH} \leftarrow$ Gender & $.06(.04)$ & $.05(.06)$ & $.07(.05)$ & $.08(.05)$ & $.04(.05)$ & $.06(.05)$ & $.05(.08)$ \\
\hline $\mathrm{APH} \leftarrow \mathrm{Mig}$ & $.11 *(.06)$ & $.10(.06)$ & $.06(.06)$ & $.04(.06)$ & $.05(.06)$ & $.05(.06)$ & $.22 *(.09)$ \\
\hline $\begin{array}{l}\mathrm{APH} \leftarrow \\
\text { CultCap }\end{array}$ & $.00(.02)$ & $.00(.03)$ & $.01(.02)$ & $.01(.02)$ & $-.00(.02)$ & $.01(.03)$ & $-.01(.04)$ \\
\hline $\begin{array}{l}\mathrm{APH} \leftarrow \\
\text { Performance }\end{array}$ & & $-.00(.00)$ & $-.00(.00)$ & $-.00(.00)$ & $-.03(.03)$ & $-.05(.03)$ & $-.00(.01)$ \\
\hline $\mathrm{APH} \leftarrow$ Rules & & & $.17 *(.05)$ & & & & \\
\hline $\begin{array}{l}\mathrm{APH} \leftarrow \\
\quad \text { Disruptions }\end{array}$ & & & & $.10 *(.03)$ & & & \\
\hline $\begin{array}{l}\mathrm{APH} \leftarrow \\
\text { TempRNO }\end{array}$ & & & & & $.13 *(.03)$ & & \\
\hline $\begin{array}{l}\text { APH } \leftarrow \text { Error } \\
\text { Culture }\end{array}$ & & & & & & $.07 *(.03)$ & \\
\hline \multicolumn{8}{|l|}{ Between class level } \\
\hline $\mathrm{APH} \leftarrow \mathrm{PH}$ & & $.09 *(.05)$ & $.10 *(.04)$ & $.10 *(.04)$ & $.11 *(.04)$ & $.08^{\sim}(.04)$ & $.05(.07)$ \\
\hline $\mathrm{APH} \leftarrow \mathrm{PAvg}$ & & $.01(.05)$ & $.00(.04)$ & $.01(.04)$ & $.02(.04)$ & $-.03(.04)$ & $-.01(.07)$ \\
\hline $\mathrm{APH} \leftarrow$ Rules & & & $.22^{\sim}(.12)$ & & & & \\
\hline $\begin{array}{l}\mathrm{APH} \leftarrow \\
\quad \text { Disruptions }\end{array}$ & & & & $.17^{\sim}(.09)$ & & & \\
\hline $\begin{array}{l}\mathrm{APH} \leftarrow \\
\mathrm{TempRNO}\end{array}$ & & & & & $.20 *(.10)$ & & \\
\hline $\begin{array}{l}\mathrm{APH} \leftarrow \text { Error } \\
\text { Culture }\end{array}$ & & & & & & $.25 *(.10)$ & \\
\hline $\begin{array}{l}\text { APH } \leftarrow \\
\text { Differentia- } \\
\text { tion }\end{array}$ & & & & & & & $.12 *(.05)$ \\
\hline $\begin{array}{l}\mathrm{PH} \leftarrow \\
\text { Realschule }\end{array}$ & & $-.05(.25)$ & $-.06(.25)$ & $-.06(.25)$ & $-.06(.25)$ & $-.06(.25)$ & $-.14(.30)$ \\
\hline $\begin{array}{l}\text { PAvg } \leftarrow \\
\quad \text { Realschule }\end{array}$ & & $-.05(.25)$ & $-.06(.25)$ & $-.06(.25)$ & $-.06(.25)$ & $-.06(.25)$ & $-.14(.30)$ \\
\hline $\begin{array}{l}\mathrm{PH} \leftarrow \\
\quad \text { Gesamtschule }\end{array}$ & & $-.32(.23)$ & $-.32(.23)$ & $-.32(.23)$ & $-.32(.23)$ & $-.32(.23)$ & $-.28(.30)$ \\
\hline $\begin{array}{l}\text { PAvg } \leftarrow \\
\quad \text { Gesamtschule }\end{array}$ & & $-.32(.23)$ & $-.32(.23)$ & $-.32(.23)$ & $-.32(.23)$ & $-.32(.23)$ & $-.28(.30)$ \\
\hline \multicolumn{8}{|l|}{ Covariances } \\
\hline $\mathrm{PH} \leftrightarrow$ PAvg & & $-.72 *(.21)$ & $-.72 *(.21)$ & $-.72 *(.21)$ & $-.72 *(.21)$ & $-.72 *(.21)$ & $-.66 *(.26)$ \\
\hline $\mathrm{AIC}$ & $71,062.6$ & $118,233.2$ & $114,917.0$ & $115,951.5$ & $62,448.8$ & $61,816.6$ & $66,172.5$ \\
\hline $\mathrm{BIC}$ & $71,541.8$ & $118,874.0$ & $115,561.9$ & $116,597.2$ & $63,094.0$ & $62,460.7$ & $66,736.9$ \\
\hline
\end{tabular}

Reference group for school type = Gymnasium

APH students' attitudes towards performance heterogeneity, Mig students' migration background $(0=$ both parents born in Germany; 1 = at least one parent born abroad), Gender ( $0=$ male; $1=$ female), CultCap cultural capital, TempRNO temporal reference norm orientation, $P H$ performance heterogeneity, $P A v g$ average performance

$\tilde{p}<.10 ; * p<.05$

\section{Teacher behavior}

Hypotheses $2 \mathrm{a}$ and $2 \mathrm{~b}$ examined how effective classroom management is associated with students' APH. Model 2 showed that if teachers implement rules in the classroom, students show a higher APH $(\beta=.17 ; p<.001)$. Model 3 revealed that students' APH is higher, if teachers apply an effective approach to manage disturbances $(\beta=.10 ; p<.01)$. Hypotheses $3 \mathrm{a}$ and $3 \mathrm{~b}$ 
investigated the relationship between a leaner-centered teaching approach and students' APH. Model 4 showed that a temporal RNO goes along with higher students' APH $(\beta=.13 ; p<.001)$. Model 5 revealed that students show a more positive APH if their teacher fosters a positive error culture $(\beta=.07 ; p<.05)$. Alongside the positive correlation on level 1 , the results revealed additional compositional relationships. Thus, beyond students' individual perception, a classes' shared perception of their teacher implementing rules $(\beta=.22 ; p<.10)$, managing disruptions $(\beta$ $=.17 ; p<.10)$, adopting a temporal $\mathrm{RNO}(\beta=.20 ; p<.05)$, and implementing a positive error culture $(\beta=.25 ; p<.05)$ positively correlates with students' APH. Model 6 focused on the professional management of performance heterogeneity through differentiated instruction, which was found to have a positive link to students' APH. Hence, if teachers differentiate their instruction more, students show a more positive APH $(\beta=.12 ; p<.05)$.

In model 6 , performance heterogeneity no longer showed a positive correlation with students' APH $(\beta=.05 ; p=.486)$. To examine this diminishing relationship, we conducted a post hoc mediation analysis (see Fig. 3). In this analysis, we assumed that performance heterogeneity would positively relate to the extent to which a teacher differentiated instruction, which, in turn, relates to students' APH. The results confirmed that a higher performance heterogeneity in a class comes along with a higher extent of differentiated instruction $(\beta=.66$; $p<.01)$ and that differentiated instruction comes along with a higher students' APH $(\beta=.12 ; p$ $<.05)$. Still, PH showed no significant correlation with APH $(\beta=.05 ; p=.468)$.

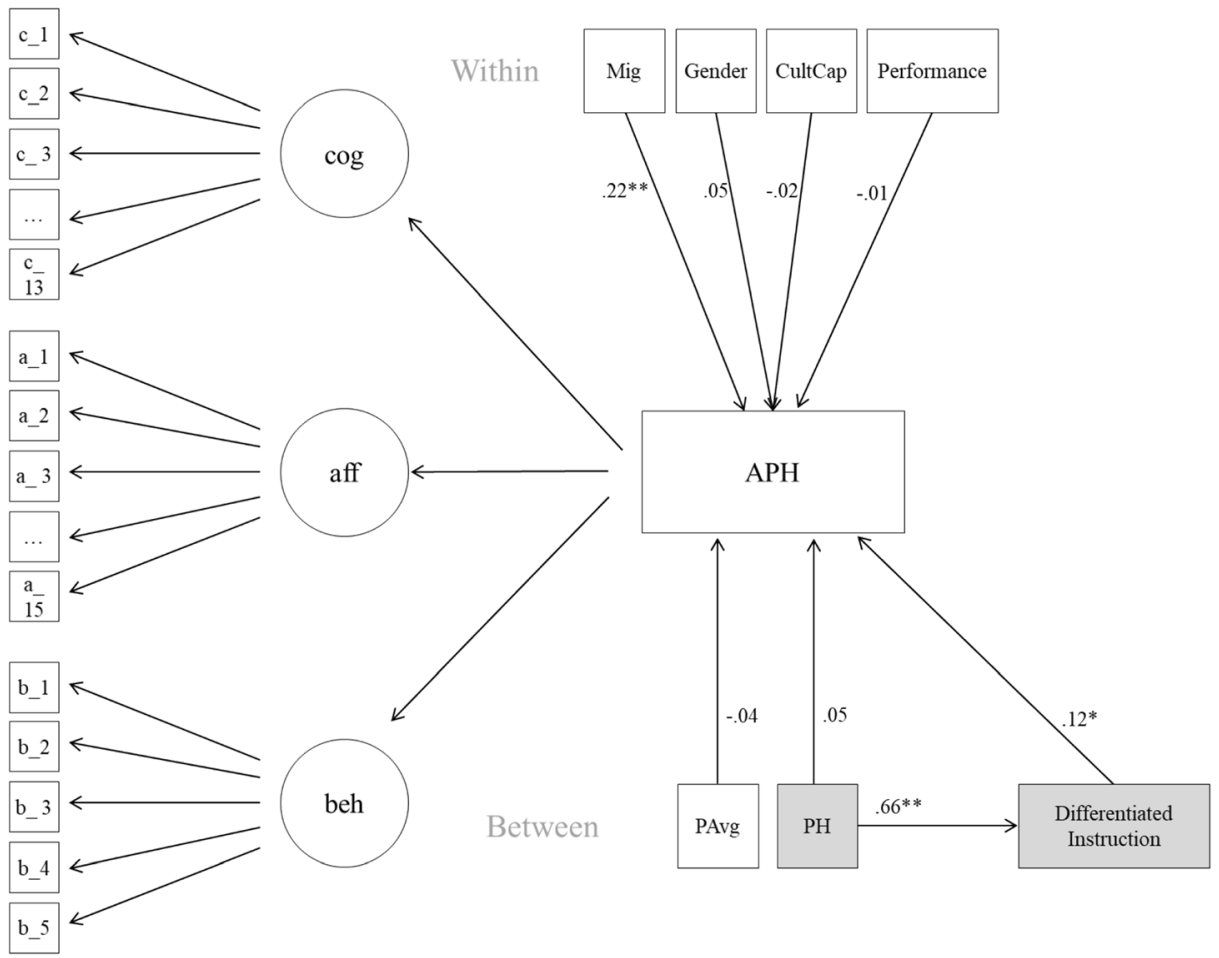

Fig. 3 Paths and results for the post hoc mediation analysis (simplified figure). cog, cognitive component; aff, affective component; beh, behavioral component; APH, students' attitudes towards performance heterogeneity; Mig, students' migration background ( $0=$ both parents born in Germany; $1=$ at least one parent born abroad); Gender ( 0 = male; 1 = female); CultCap, cultural capital; PH, performance heterogeneity; PAvg, average performance 


\section{Discussion}

Our analyses reveal four important findings. First, students have a rather positive APH. Second, compared to contextual factors, individual variables play a minor role when analyzing students' APH. Third, a heterogeneous class composition positively correlates with APH among students. Fourth, students' APH is higher in classes in which teachers apply a professional approach of managing performance heterogeneity.

Our findings show that students have a rather positive APH. Accordingly, students exhibit positive beliefs, positive emotions, and an average behavioral intention regarding performance heterogeneity. The three components correlate positively and highly significantly. Thus, students with more positive beliefs about performance heterogeneity also show more positive emotions and are more positive about choosing a heterogeneous class. This confirms the basic assumption of the consistency theorem in multi-dimensional attitude theory (Eagly \& Chaiken, 1993) that the different components are generally consistent.

However, the behavioral component differs slightly from the cognitive and affective components with regard to its mean and distribution. The descriptive characteristics show that the response pattern changes when students assess their intentional behavior regarding a heterogeneous class. The distribution function shows that students do not clearly prefer a moderately heterogeneous classthere rather is a similar number of students who would choose a homogeneous, heterogeneous, or moderately heterogeneous class. The difference between the behavioral component and the cognitive and affective components is also revealed by the respective correlations. Although positive correlations were found between the attitude components, the cognitive and affective components were much more strongly related than the behavioral component. Attitude research has extensively discussed the fact that the behavioral component deviates from the cognitive and affective components (e.g., Eagly \& Chaiken, 1993; Fishbein \& Ajzen, 1975; Rosenberg, 1960). The construal level theory assumes that psychological distances and mental abstractions influence each other. Individuals think more abstractly about distant objects and more concretely about close objects (Liberman \& Trope, 2008). Believing that a heterogeneous class is good or bad and feeling that a heterogeneous class is good or bad is a distant, abstract construct. As soon as students are asked to decide on a certain class composition, the attitude object performance heterogeneity is evaluated based on their current individual state. As a result, students have higher attitude values for the cognitive and affective components, and some students would choose a homogeneous class despite their positive cognitive and affective attitude.

Another central finding of our analyses is the relationship between performance heterogeneity itself and students' APH. In accordance with the contact hypothesis, being part of a heterogeneous class positively correlates with students' APH (Allport, 1954). Heterogeneity is a critically discussed topic in the media and everyday school life. Students from heterogeneous classes might be able to weigh up the advantages of heterogeneity and be less affected by negative stereotypes. Our results reveal one exception: Performance heterogeneity does not show a significant correlation if the extent of differentiated instruction is taken into account. A post hoc mediation analysis provided the deeper insight that performance heterogeneity is positively linked to the extent of differentiated instruction, which again positively relates to students' APH.

An additional central finding of our analysis is the relationship between teachers' behavior and students' APH. Especially, students in heterogeneous classes strongly differ in performance. Disturbances might arise more often, because students feel bored or overstrained. Furthermore, incorrect answers might occur more frequently, comprehension questions might be asked more often, and the time to finish an assignment might vary considerably. Each of these factors can 
negatively relate to APH among students, because students have difficulties dealing with such characteristics of heterogeneity. Therefore, it is important that teachers themselves implement strategies to professionally deal with heterogeneity. In doing so, they stress the advantages derived from a heterogeneous context and strengthen the positive relationship with students' APH.

In that respect, our results prove that professional management of performance heterogeneity by teachers - classroom management, a learner-centered teaching approach, and differentiated instruction - positively relates to students' APH. Our results reveal that students' APH is higher in classes, in which teachers effectively manage their classrooms by implementing rules and dealing with disturbances. In this way, teachers have more capacity for performing instruction, supporting individual learning, mobilizing groups, and facilitating social negotiation processes (Doyle, 2006; Evertson et al., 2006). As already stated in the theoretical section, disturbances might negatively affect students' APH. However, if teachers keep this disadvantage to a minimum (e.g., by dealing with disturbances using eye contact or by involving the respective students), students might not be irritated by heterogeneity and be more likely to have a positive APH. In addition, our results show that a learner-centered teaching approach integrating a temporal RNO and a positive error culture is positively linked to students' APH. Performancerelated differences between students can increase the separation between high- and lowperforming students and tense the classroom atmosphere, coming along with a negative APH among students. If teachers give performance-related feedback using temporal RNO, they focus on the development of students' individual performance instead of inter-individual comparisons. Thus, this feedback approach is assumed to positively relate to students' APH. However, the results regarding RNO must be interpreted carefully: the ICC1 and ICC2 are very low, hinting that students within a class do not resemble one another regarding their perception of a teacher's RNO. The effect of RNO on class level 2 on students' APH might be estimated inaccurately, and a careful interpretation is needed. Besides RNO, teachers can actively incorporate incorrect answers into instruction using a positive error culture to support students' APH. By fostering a positive error culture, teachers convey their appreciation of misunderstandings and misconceptions to students, enabling students to feel comfortable in a heterogeneous class. Furthermore, differentiated instruction was found to positively relate to students' APH. When applying differentiated instruction, teachers keep in mind the complexity and variety of teaching-learning environments. This is especially important in heterogeneous classes, in which student performance highly differs. Some studies show that differentiated instruction has advantages for social learning compared to traditional teaching (e.g., Lüders \& Rauin, 2004; Trautmann \& Wischer, 2011). Especially, cooperative approaches such as peerassisted learning strategies or reciprocal teaching involving tutors and tutees of different ability levels (Chatoupis \& Vagenas, 2018; Fuchs et al., 1997; Hattie, 2009; Palincsar \& Brown, 1984; Pilten, 2016) stimulate classroom settings and lead students to perceive performance-related heterogeneity in the classroom positively.

Besides baseline model 0, model 6 reveals a significant positive relationship with students' migration background on APH. This effect must be interpreted carefully. The sample's composition regarding migration background in this study might differ to that of other studies, because students' countries of origin are very diverse in our study. Researchers have already shown that when analyzing students' migration background, differential effects must be considered, since the effects of subgroups from different countries of origin differ (e.g., Müller \& Stanat, 2006; Segeritz et al., 2010). In our study, origin-related correlations could not be identified because of the small sample size, and before putting forward alternative explanations, this link should be replicated in future studies. 


\section{Limitations}

When interpreting our results, the following limitations have to be considered. First and most important, our study does not allow the interpretation of causal relationships, even if a direction of effects derives from theory. According to the theoretical section, we can assume that performance heterogeneity and a teachers' effective approach to deal with it increase students' APH. Furthermore, the reverse case, that APH influences teacher action, is difficult to explain in theory. However, there is no empirical evidence from our study, since data were collected at a mutual measurement point. Additionally, our data were collected in the first quarter of the school year; thus, students had been in the same class for only about 2 months. However, the variance of the attitude scale and the systematic correlations indicate that students had already gained an impression of the performance heterogeneity in their classroom. Secondly, our data only cover $5^{\text {th }}$-grade students. Although a preliminary study with guided interviews (Dotzel \& Karst, 2021) has shown that even young students can grasp the performance heterogeneity construct, it remains questionable if older students show the same patterns. Furthermore, we must consider the specificity of our sample, in which $65 \%$ of the students had a migration background and transferability to regions with fewer students with migration backgrounds in schools (e.g., rural schools) can be seen critically. Another limitation was the focus on the subject German. Although studies show that language proficiency is a good predictor for school success and performance in other subjects (Watson et al., 2003), we cannot assume that students' APH would be similar for mathematics or a foreign language. Future analyses are needed to reveal whether the results are comparable for these subjects. Another important limitation is the lack of the variable teachers' APH. Studies have already shown that teachers of heterogeneous classes show more positive attitudes (e.g., Dar, 1985; Hartinger et al., 2010; Linchevski \& Kutscher, 1998). A teachers' APH can reinforce the relationship between performance heterogeneity and students' APH, since the teacher plays an important role in dealing with this heterogeneity. In addition, variables on classroom management and learner-centered approach were collected via student judgments. Accordingly, we have to address the critical question of the validity of student assessment. According to Clausen (2002), however, student judgment is considered particularly valid when the areas of teacher action require little didactic-pedagogical knowledge. For assessing the variables we used in our study, pedagogical-didactic knowledge is especially required for differentiated instruction, which we assessed by teacher judgments. Furthermore, most of the student-judged variables (implementing rules, managing disturbances and positive error culture) were assessed by scales developed by Piwowar (2013). The author used several tests to validate the scales for classroom management and learner-centered approach, and analyses revealed that the student assessment gave a valid picture of the variables (Piwowar, 2013). Therefore, we can be reasonably sure of a valid measurement of these variables on the class level. A valid assessment of the temporal RNO on the class level must still be viewed from a critical perspective, as was also outlined in the "Discussion" section. Finally, the relatively small number of classes should be considered when interpreting our results. The effects of performance heterogeneity and differentiated instruction are affected by class size. In comparison to models 2-5, there are no student level 1 data available (accordingly, averaging outliers is not possible). Hence, follow-up analyses with a larger sample at class level are necessary to replicate our findings.

\section{Practical implications and conclusions}

Our study shows that APH tends to be positive among students. Regarding this, it is of high relevance that individual background characteristics are not as important for students' APH as their 
teacher's behavior. This is an advantage for learning and instruction, because individual characteristics cannot be influenced by teachers and therefore cannot be used to change students' APH. Furthermore, it is of great importance that students' APH positively relates to a teachers implementation of classroom management, of learner-centered teaching, and of differentiated instruction. Numerous studies have already proven that the application of these methods in the classroom enhances students' learning (e.g., Kunter \& Voss, 2011; Pianta \& Hamre, 2009; Rakoczy et al., 2007). Furthermore, students' learning improves with positive school-related attitudes among students (e.g., Else-Quest et al., 2013; Gaith \& Bouzeineddine, 2011; Papanastasiou \& Zembylas, 2002). Under the assumption that teachers actually influence students' APH - as assumed in theory - teachers can have a dual effect on students' learning: first, via the direct effect of creating a clear, positive, and differentiated learning environment, and second, via the indirect effect of these factors, through which teachers support learning by positively changing students' APH.

Supplementary Information The online version contains supplementary material available at https://doi.org/ 10.1007/s10212-021-00544-2.

Funding Open Access funding enabled and organized by Projekt DEAL. This research was supported by grants from the Ministry of Science, Research, and the Arts in Baden-Württemberg, funding line "Leuchttürme Lehrerbildung".

Open Access This article is licensed under a Creative Commons Attribution 4.0 International License, which permits use, sharing, adaptation, distribution and reproduction in any medium or format, as long as you give appropriate credit to the original author(s) and the source, provide a link to the Creative Commons licence, and indicate if changes were made. The images or other third party material in this article are included in the article's Creative Commons licence, unless indicated otherwise in a credit line to the material. If material is not included in the article's Creative Commons licence and your intended use is not permitted by statutory regulation or exceeds the permitted use, you will need to obtain permission directly from the copyright holder. To view a copy of this licence, visit http://creativecommons.org/licenses/by/4.0/.

\section{References}

Allport, G. (1954). The nature of prejudice. Doubleday Anchor Books.

Anderson, L. M., Evertson, C. M., \& Brophy, J. E. (1979). An experimental study of effective teaching in first grade groups. Elementary School Journal, 79(1), 193-223. https://doi.org/10.1086/461151.

Armstrong, M. M., Morris, C., Abraham, C., \& Tarrant, M. (2016). Interventions utilising contact with people with disabilities to improve children's attitudes towards disability: A systematic review and meta-analysis. Disability and Health Journal, 10(1), 11-22. https://doi.org/10.1016/j.dhjo.2016.10.003.

Authors (2021)

Avramidis, E., \& Norwich, B. (2002). Teachers attitudes towards integration inclusion a review of the literature. European Journal of Special Needs Education, 17(2), 129-147. https://doi.org/10.1080/ 08856250210129056.

Baumert, J., Blum, W., Brunner, M., Dubberke, T., Jordan, A., Klusmann, U. et al. (2008). Professionswissen von Lehrkräften, kognitiv aktivierender Mathematikunterricht und die Entwicklung von mathematischer Kompetenz (COACTIV): Dokumentation der Erhebungsinstrumente [Professional knowledge of teachers, cognitively activating mathematics teaching and the development of mathematical competence (COACTIV): documentation of the survey instruments]. Max-Planck-Institut für Bildungsforschung.

Baumert, J., Lehmann, R., Lehrke, M., Schmitz, B., Clausen, M., Hosenfeld, I., et al. (1997). TIMSS Mathematisch-naturwissenschaftlicher Unterricht im internationalen Vergleich: deskriptive Befunde [TIMSS - Teaching mathematics and science in international comparison: Descriptive findings]. Leske + Budrich. https://doi.org/10.1007/978-3-322-95096-3.

Bem, D. J. (1972). Self-perception theory. In L. Berkowitz (Ed.), Advances in experimental social psychology (Vol. 6, pp. 1-62). Academic Press. https://doi.org/10.1016/S0065-2601(08)60024-6.

Bloom, B. S. (1976). Human characteristics and school learning. McGraw-Hill. 
Brophy, J. (1986). Classroom management techniques. Education and Urban Society, 18(2), 182-194. https:// doi.org/10.1177/0013124586018002005.

Brophy, J. E., \& Evertson, C. M. (1976). Learning from teaching: A developmental perspective. Allyn \& Bacon. https://doi.org/10.1002/1520-6807(197710)14:4<525::AID-PITS2310140430>3.0.CO;2-Z.

Browne, M. W., \& Cudeck, R. (1993). Alternative ways of assessing model fit. In K. A. Bollen, \& J. S. Long (Eds.), Testing structural equation models (pp. 136-162). Sage. doi:https://doi.org/10.1177/ $0049124192021002005,21,2$

Bundesamt, S. (2018). Bevölkerung und Erwerbstätigkeit, Bevölkerung mit Migrationshintergrund, Ergebnisse des Mikrozensus 2017 [Population and employment, population with migration background, results of the microcensus 2017]. Destatis.

Byrne, B. M. (1994). Structural equation modeling with EQS and EQS/Windows. Sage Publications.

Byrnes, D. A., \& Kiger, G. (1997). Teachers attitudes about language diversity. Teaching and Teacher Education, 13(6), 637-644. https://doi.org/10.1016/S0742-051X(97)80006-6.

Chatoupis, C., \& Vagenas, G. (2018). Effectiveness of the practical style and reciprocal style of teaching: A meta-analysis. The Physical Educator, 75, 175-194. https://doi.org/10.18666/TPE-2018-V75-I2-7920.

Cho, G., \& DeCastro-Ambrosetti, D. (2005). Is ignorance bliss? Preservice-teachers' attitudes toward multicultural education. The High School Journal, 89(2), 24-28. https://doi.org/10.1353/hsj.2005.0020.

Cornelius-White, J. (2007). Learner-centered teacher-student relationships are effective: A meta-analysis. Review of Educational Research, 77(1), 113-143. https://doi.org/10.3102/003465430298563.

Dar, Y. (1985). Teachers attitudes towards ability grouping: Educational considerations and social organizational influences. Interchange, 16(2), 17-28. https://doi.org/10.1007/BF01807206.

Dickhäuser, O., Janke, S., Praetorius, A.-K., \& Dresel, M. (2017). The effects of teachers' reference norm orientations on students' implicit theories and academic self-concepts. Zeitschrift für Pädagogische Psychologie, 31(3-4), 205-219. https://doi.org/10.1024/1010-0652/a000208.

Dotzel, S. \& Karst, K. (2021). Einstellung zur Leistungsheterogenität bei Schülerinnen und Schülern. Wie können sie gemessen werden, wie sind sie ausgeprägt und wie können sie beeinflusst werden? [Attitudes towards performance heterogeneity among students. How can they be measured, which value do they have and how can they be influenced?] In K. Karst, D. Thoma, J. Seifried, J. Derkau \& S. Münzer (Hrsg.), Lehrer*innenbildung im Kontext leistungsbezogener Heterogenität und Mehrsprachigkeit von Schüler*innen [Teacher education in the context of performance heterogeneity and multilingualism of students]. Münster: Waxmann.

Dooly, M. (2005). How aware are they? Research into teachers attitudes about linguistic diversity. Language Awareness, 14(2/3), 97-111. https://doi.org/10.1080/09658410508668827.

Doyle, W. (2006). Ecological approaches to classroom management. In C. M. Evertson \& C. S. Weinstein (Eds.), Handbook of classroom management (pp. 97-125). Lawrence Erlbaum.

Eagly, A. H., \& Chaiken, S. (1993). Psychology of attitudes. Harcourt Brace Jovanovich College Publishers. https://doi.org/10.1002/mar.4220120509.

Else-Quest, N. M., Mindeo, C. C., \& Higgins, A. (2013). Math and science attitudes and achievement at the intersection of gender and ethnicity. Psychology of Women Quarterly, 37(3), 293-309. https://doi.org/10. $1177 / 0361684313480694$

Emmer, E. T., Evertson, C. M., \& Worsham, M. E. (2006). Classroom management for middle and high school teachers (Vol. 7). Allyn \& Bacon.

Enders, C. K., \& Tofighi, D. (2007). Centering predictor variables in cross-sectional multilevel models: A new look at an old issue. Psychological Methods, 12(2), 121-138. https://doi.org/10.1037/1082-989X.12.2.121.

Evertson, C. M., \& Emmer, E. T. (1982). Preventive classroom management. In D. Duke (Ed.), Helping teachers manage classrooms. Association for Supervision and Curriculum Development.

Evertson, C. M., Emmer, E. T., \& Worsham, M. E. (2006). Classroom management for elementary teachers (Vol. 7). Allyn \& Bacon.

Fishbein, M., \& Ajzen, I. (1975). Belief, attitude, intention, behavior. Addison-Wesley.

Fuchs, D., Fuchs, L. S., Mathes, P. G., \& Simmons, D. C. (1997). Peer-assisted learning strategies: Making classrooms more responsive to diversity. American Educational Research Journal, 34(1), 174-206. https:// doi.org/10.3102/00028312034001174.

Gaith, G., \& Bouzeineddine, A. R. (2003). Relationships between reading attitudes, achievement, and learners' perception of their Jigsaw II cooperative learning experience. Reading Psychology, 24(2), 105-121. https:// doi.org/10.1080/02702710390197444.

Hartinger, A., Grittner, F., Lang, E., \& Rehle, C. (2010). Ein Vergleich der Einstellung zur Heterogenität von Lehrkräften in jahrgangsgemischten und jahrgangshomogenen Klassen [A comparison of attitudes towards heterogeneity of teachers in mixed and homogeneous classes]. In K.-H. Arnold, K. Hauenschild, B. Schmidt, \& B. Ziegenmeyer (Eds.), Zwischen Fachdidaktik und Stufendidaktik. Perspektiven für die 
Grundschulforschung [Between subject didactics and grade didactics. Perspectives for primary school research] (pp. 77-80). VS Verlag für Sozialwissenschaften. https://doi.org/10.1007/978-3-531-92475-5_1.

Hattie, J. A. C. (2009). Visible learning: A synthesis of over 800 meta-analyses relating to achievement. Routledge. doi:https://doi.org/10.1080/00071005.2011.584660, 59, 2, 197, 201

Jensen, P., \& Rasmussen, A. W. (2011). The effect of immigrant concentration in schools on native and immigrant children's reading and math skills. Economics of Education Review, 30(6), 1503-1515. https:// doi.org/10.1016/j.econedurev.2011.08.002.

Jerusalem, M., Drössler, S., Kleine, D., Klein-Heßling, J., Mittag, W., \& Röder, B. (2009). Skalen zur Erfassung von Lehrer- und Schülermerkmalen. Schülerperzipierte Lehrerbezugsnormorientierung (SPLB) [Scales for measuring teacher and student characteristics. Student-perceived teacher reference norm orientation (SPLB)]. Retrieved from https://www.erziehungswissenschaften.hu-berlin.de/de/paedpsych/forschung/ Skalenbuch_FoSS.pdf.

Karst, K., Dotzel, S., Stark, M., Derkau, J. \& Münzer, S. (2021). Diagnostik im Unterricht unterstützt durch Kooperationen in Campus Community-Partnerschaften [Diagnostics in the classroom supported by cooperation in Campus Community Partnerships]. In K. Karst, D. Thoma, J. Seifried, J. Derkau \& S. Münzer (Hrsg.), Lehrer*innenbildung im Kontext leistungsbezogener Heterogenität und Mehrsprachigkeit von Schüler*innen [Teacher education in the context of performance heterogeneity and multilingualism of students]. Münster: Waxmann

Katz, D., \& Stotland, E. (1959). A preliminary statement to a theory of attitude structure and change. In S. Koch (Ed.), Psychology: A study of a science (Vol. 3, pp. 423-457). McGraw-Hill.

Keith, N., \& Frese, M. (2008). Effectiveness of error management training: a meta-analysis. Journal of Applied Psychology, 93(1), 59-69. https://doi.org/10.1037/0021-9010.93.1.59.

King-Sears, M. E. (2008). Differentiation and the Curriculum. Facts and fallacies: Differentiation and the general education curriculum for students with special educational needs. Blackwell Publishing. https://doi. org/10.1111/j.1467-9604.2008.00371.x.

Kline, R. B. (1998). Principles and practice of structural equation modeling. Guilford Press.

Krosnick, J. A., \& Petty, R. E. (1995). Attitude strength: Antecedents and consequences. Lawrence Erlbaum.

Kumar, R., \& Hamer, L. (2012). Preservice teachers' attitudes and beliefs toward student diversity and proposed instructional practices: a sequential design study. Journal of Teacher Education, 64(2), 162-177. https://doi. org/10.1177/0022487112466899.

Kunter, M., \& Trautwein, U. (2013). Psychologie des Unterrichts [Psychology of teaching]. Schöningh.

Kunter, M., \& Voss, T. (2011). Das Modell der Unterrichtsqualität in COACTIV: eine multikriteriale Analyse [The model of teaching quality in COACTIV: A multi-criteria analysis]. In M. Kunter, J. Baumert, W. Blum, U. Kusmann, S. Krauss, \& M. Neubrand (Eds.), Professionelle Kompetenz von Lehrkräften - Ergebnisse des Forschungsprogramms COACTIV [Professional competence of teachers - Results of the COACTIV research programme] (pp. 85-113). Münster: Waxmann.

Larson, R., \& Richards, M. (1991). Boredom in the middle school years: blaming schools versus blaming students. American Journal of Education, 99(4), 418-443. https://doi.org/10.1086/443992.

Liberman, N., \& Trope, Y. (2008). The psychology of transcending the here and now. Science, 322(5905), 12011205. https://doi.org/10.1126/science.1161958.

Lieberson, S. (1969). Measuring population diversity. American Sociological Review, 34(6), 850-862. https:// doi.org/10.2307/2095977.

Linchevski, L., \& Kutscher, B. (1998). Tell me with whom you're learning, and I'll tell you how much you've learned: Mixed-ability versus same-ability grouping in mathematics. Journal for Research in Mathematics Education, 29(5), 533-554. https://doi.org/10.2307/749732.

Lüders, M., \& Rauin, U. (2004). Unterrichts- und Lehr-Lernforschung [Research in teaching and learning]. In W. Helsper \& J. Böhme (Eds.), Handbuch der Schulforschung [Handbook of school research] (pp. 691-720). VS Verlag für Sozialwissenschaften. https://doi.org/10.1007/978-3-531-91095-6.

Maehler, D., \& Brinkman, H. U. (2016). Methoden der Migrationsforschung - Ein interdisziplinärer Forschungsleitfaden [Methods of migration research - An interdisciplinary research guide]. Springer VS. https://doi.org/10.1007/978-3-658-10394-1.

Markic, S., \& Abels, S. (2014). Heterogeneity and diversity. A growing challenge or enrichment for science education in German schools? Eurasia Journal of Mathematics, Science \& Technology Education, 10(4), 271-283. https://doi.org/10.12973/eurasia.2014.1082a.

Martinez, R. S., Aricak, O. T., \& Jewell, J. (2008). Influence of reading attitudes on reading achievement: A test of the temporal-interaction model. Psychology in the Schools, 45(10), 1010-1022. https://doi.org/10.1002/ pits. 20348.

McCombs, B. L., \& Whisler, J. S. (1997). The learner-centered classroom and school: Strategies for increasing student motivation and achievement. Jossey-Bass. 
McGinnis, J. C., Frederick, B. P., \& Edwards, R. (1995). Enhancing classroom management trough proactive rules and procedures. Psychology in the Schools, 32(3), 220-224. https://doi.org/10.1002/15206807(199507)32:3<220::AID-PITS2310320309>3.0.CO;2-4.

Müller, A. G., \& Stanat, P. (2006). Schulischer Erfolg von Schülerinnen und Schülern mit Migrationshintergrund: Analysen zur Situation von Zuwanderern aus der ehemaligen Sowjetunion und aus der Türkei [Academic success of students with migration background: Analyses of the situation of immigrants from the former Soviet Union and Turkey]. In J. Baumert, P. Stanat, \& R. Watermann (Eds.), Herkunftsbedingte Disparitäten im Bildungswesen: Differenzielle Bildungsprozesse und Probleme der Verteilungsgerechtigkeit [Origin-related disparities in education: Differential educational processes and problems of distributive equity] (pp. 221-255). VS Verlag für Sozialwissenschaften. https://doi.org/10.1007/ 978-3-531-90082-7_6.

Nordstrom, C. R., Wendland, D., \& Williams, K. B. (1998). "To err is human": An examination of the effectiveness of error management training. Journal of Business and Psychology, 12(3), 269-282. https:// doi.org/10.1023/A:1025019212263.

Nowicki, E. A., \& Sandieson, R. (2002). A meta-analysis of school-age children's attitudes towards persons with physical or intellectual disabilities. International Journal of Disability, Development and Education, 49(3), 243-265. https://doi.org/10.1080/1034912022000007270.

Palincsar, A. S., \& Brown, A. L. (1984). Reciprocal teaching of comprehension-fostering and comprehensionmonitoring activities. [Empirical study]. Cognition and Instruction, 1(2), 117-175. https://doi.org/10.1207/ s1532690xci0102 1.

Papanastasiou, E. C., \& Zembylas, M. (2002). The effect of attitudes on science achievement: A study conducted among high school pupils in Cyprus. International Review of Education, 48(6), 469-484. https://doi.org/10. 1023/A:1021334424571.

Papanastasiou, E. C., \& Zembylas, M. (2004). Differential effects of science attitudes and science achievement in Australia, Cyprus, and the USA. International Journal of Science Education, 26(3), 259-280. https://doi. org/10.1080/0950069022000038277.

Pedota, P. (2007). Strategies for effective classroom management in the secondary setting. The Clearing House, 80(4), 163-166. https://doi.org/10.3200/TCHS.80.4.163-168.

Perkins, R. E., \& Hill, A. B. (1985). Cognitive and affective aspects of boredom. British Journal of Psychology, 76(2), 221-234. https://doi.org/10.1111/j.2044-8295.1985.tb01946.x.

Pianta, R. C., \& Hamre, B. K. (2009). Conzeptualization, measurement, and improvement of classroom processes: Standardized observation can leverage capacity. Educational Researcher, 38(2), 109-119. https://doi.org/10.3102/0013198X09332374.

Pietsch, M. (2010). Evaluation von Unterrichtsstandards [Evaluation of classroom teaching standards]. Zeitschrift für Erziehungswissenschaft, 1(13), 121-148. https://doi.org/10.1007/s11618-010-0113-z.

Pilten, G. (2016). The evaluation of effectiveness of reciprocal teaching strategies on comprehension of expository texts. Journal of Education and Training Studies, 4(10), 232-247. https://doi.org/10.11114/ jets.v4i10.1791.

Piwowar, V. (2013). Multidimensionale Erfassung von Kompetenzen in Klassenmanagement. Konstruktion und Validierung eines Beobachter- und eines Schülerfragebogens [The multidimensional assessment of classroom management competencies: construction and validation of an observer rating and a student rating for secondary teachers]. Zeitschrift für Pädagogische Psychologie, 27(4), 215-228. https://doi.org/10.1024/ 1010-0652/a000108.

Powell, J. (2006). Special education and the risk of becoming less educated. European Societies, 8(4), 577-599. https://doi.org/10.1080/14616690601002673.

R Core Team. (2019). R: A language and environment for statistical computing. R Foundation for Statistical Computing Retrieved from https://www.R-project.org/.

Rach, S., Ufer, S., \& Heinze, A. (2013). Learning from errors: Effects of teachers' training on students' attitudes towards and their individual use of errors. PNA, 8(1), 21-30. https://doi.org/10.30827/pna.v8i1.6122.

Rakoczy, K., Klieme, E., Drollinger-Vetter, B., Lipowsky, F., Pauli, C., \& Reusser, K. (2007). Structure as quality feature in mathematics instruction of the learning environment vs. a structured presentation of learning content. In M. Prenzel (Ed.), Studies on the educational quality of schools. The final report of the DFG Priority Programme (pp. 101-120). Waxmann.

Rheinberg, F. (1980). Leistungsbewertung und Lernmotivation [Performance evaluation and motivation for learning]. Hogrefe.

Rosenberg, M. J. (1960). An analysis of affective-cognitive consistency. In C. I. Hovland \& M. J. Rosenberg (Eds.), Attitude organization and change. Yale University Press.

Rosenberg, M. J., \& Hovland, C. I. (1960). Cognitive, affective, and behavioral components of attitudes. In C. I. Hovland \& M. J. Rosenberg (Eds.), Attitude organization and change. Yale University Press. 
Rosseel, Y. (2012). lavaan: An R package for structural equation modeling. Journal of Statistical Software, 48(2), 1-36. https://doi.org/10.18637/jss.v048.i02.

Segeritz, M., Walter, O., \& Stanat, P. (2010). Muster des schulischen Erfolgs von jugendlichen Migranten in Deutschland: Evidenz für segmentierte Assimilation? [Patterns of academic success of adolescents migrants in Germany: Evidence for segmented assimilation?]. Kölner Zeitschrift für Soziologie und Sozialpsychologie, 62(1), 113-138. https://doi.org/10.1007/s11577-010-0094-1.

Slavin, R. E. (1990). Achievement effects of ability grouping in secondary schools: A best-evidence synthesis. Review of Educational Research, 60(3), 471-499. https://doi.org/10.3102/00346543060003471.

Teachman, J. D. (1980). Analysis of population diversity: Measures of qualitative variation. Sociological Methods \& Research, 8(3), 341-362. https://doi.org/10.1177/004912418000800305.

Theunissen, U., Schoppengerd, E., Witzke, F., Endell, A., \& Wenning, F. (2005). Duisburger Sprachstandstest. Gesamtschule Duisburg-Meiderich. [Duisburg language level test. Duisburg-Meiderich Comprehensive School]. Unveröffentlichtes Testinstrument [Unpublished test instrument].

Trautmann, M., \& Wischer, B. (2011). Heterogenität und Schule. Eine kritische Einführung [Heterogeneity and school. A critical introduction]. Springer.

Tulis, M. (2013). Error management behavior in classrooms. Teachers responses to student mistakes. Teaching and Teacher Education, 33, 56-68. https://doi.org/10.1016/j.tate.2013.02.003.

Ullman, J. B. (2001). Structural equation modeling. In B. G. Tabachnick, \& L. S. Fidell (Eds.) Using multivariate statistics (pp. 653-771). Allyn \& Bacon. doi:https://doi.org/10.1371/journal.pone.0071264, 8, 8

Van de Grift, W. (2007). Quality of teaching in four European countries: a review of the literature and application of an assessment instrument. Educational Research, 49(2), 127-152. https://doi.org/10.1080/ 00131880701369651.

Vaughn, S., Klingner, J. K., \& Bryant, D. P. (2001). Collaborative strategic reading as a means to enhance peermediated instruction for reading comprehension and content area learning. Remedial and Special Education, 22(2), 66-74. https://doi.org/10.1177/074193250102200201.

Watson, C. S., Kidd, G. R., Horner, D. G., Lowther, C. A., Eddins, D. A., Krueger, G., et al. (2003). Sensory, cognitive, and linguistic factors in the early academic performance of elementary school children: The Benton-IU project. Journal of Learning Disabilities, 36(2), 165-197. https://doi.org/10.1177/ 002221940303600209.

Youngs, C. S., \& Youngs, G. A. (2001). Predictors of mainstream teachers attitudes toward ESL students. TESOL Quarterly, 35(1), 97-120. https://doi.org/10.2307/3587861.

Publisher's note Springer Nature remains neutral with regard to jurisdictional claims in published maps and institutional affiliations.

Stefanie Dotzel. Department of Psychology, University of Bamberg, Markusplatz 3, 96047 Bamberg, Germany. Email: stefanie.dotzel@uni-bamberg.de

Current themes of research:

Elementary and lower secondary education. Attitudes. Performance heterogeneity. Linguistic diversity. Ethnic/ racial diversity. Teachers' assessment competence.

Most relevant publications in the field of Psychology of Education:

Karst, K., Dotzel, S., \& Dickhäuser, O. (2018). Comparing global judgments and specific judgments of teachers about students' knowledge. Is the whole the sum of its parts? Teaching and Teacher Education (76), 194 203. https://doi.org/10.1016/j.tate.2018.01.013 